\title{
Studi Kinetika Ekstrak Daun Binahong Terhadap Wajah yang Berjerawat
}

\author{
Hanan Habibah" \\ ${ }^{7}$ Pendidikan Kimia, FMIPA, Universitas Negeri Padang, \\ Indonesia \\ *E-mail : hananhabibah05@gmail.com
}

\begin{abstract}
Abstrak. Studi ini bertujuan untuk membuat masker dari ekstrak daun binahong untuk menghambat pertumbuhan jerawat yang terdapat di wajah. Metode yang dilakukan adalah eksperimen dan uji aktifitas katalitik secara langsung. Tahapan pertama yang dilakukan adalah dengan membuat ekstrak daun binahong. Uji aktifasi dilakukan secara langsung terhadap wajah yang berjerawat selama satu minggu pemakaian setiap harinya. Hasil eksperimen membuktikan bahwa ekstrak daun binahong dapat mengurangi jerawat pada wajah. Kondisi optimum ekstrak daun binahong tercapai pada hari ke-7 pemakaian. Berkurangnya jerawat pada wajah diduga karena aktifasi katalitik ekstrak daun binahong terhadap jerawat. Dimana di dalam daun binahong mengandung alkaloid, flavonoid dan anti oksidan yang tinggi yang berfungsi menghambat tumbuhnya jerawat pada wajah.
\end{abstract}

Kata kunci : ekstrak, daun binahong, jerawat, katalitik

\section{PENDAHULUAN}

Reaksi kimia ${ }^{17]}$ adalah perubahan yang terjadi antara dua atau lebih zat yang disebut reaktan dan menghasilkan zat baru ${ }^{[2]}$ yang disebut produk. Ciri-ciri yang menandakan terbentuknya reaksi kimia adalah adanya gelembung gas, terjadinya perubahan warna, adanya endapan ataupun perubahan suhu. Reaksi kimia ${ }^{[3]}$ dapat dipercepat menggunakan peranan katalis ${ }^{[4-6]}$

Katalis atau katalitik ${ }^{7-10]}$ merupakan zat yang dapat mempengaruhi suatu reaksi kimia. Katalis berguna untuk mempercepat atau memperlambat suatu reaksi yang akan terjadi pada suhu tertentu ${ }^{[17-21]}$. Namun katalis tidak ikut bereaksi dengan reaksi kimia tersebut. Reaksi katalitik dapat berjalan reversibel dan irreversibel. Katalis berperan terhadap suatu reaksi kimia ${ }^{[22-25]}$ tetapi bukan sebagai pereaksi ataupun sebagai produk. Di dalam reaksi kimia katalitik atau katalis dapat menurunkan energi aktifasi suatu zat. Banyak sekali ditemukanya katalis pada kehidupan sehari-hari, baik katalis alami maupun katalis buatan. Pada umumnya tumbuhan dapat menjadi katalis alami ${ }^{[26-29]}$ untuk penyembuhan beberapa penyakit. Salah satunya adalah untuk menghambat pertumbuhan jerawat pada wajah

Jerawat (acne vulgaris) ${ }^{[34-39]}$ adalah salah satu masalah terbesar bagi remaja pada umumnya. Jerawat juga merupakan hal yang lumrah terjadi pada remaja saat masa pubersitas. Namun 
dengan adanya jerawat di wajah dapat menurunkan kepercayaan diri terhadap seseorang. Faktor -faktor yang membuat timbulnya jerawat ${ }^{[40-43]}$ pada wajah adalah hormon, bakteri, pola makan yang tidak sehat, kebersihan wajah yang tidak dijaga atau bahkan saat datang bulan.

Dengan perkembangan zaman yang begitu praktis dan instan ini, berbagai cara dilakukan orang untuk membuat jerawat hilang. Salah satunya adalah membeli masker yang dijual di toko kosmetik. Namun, banyak sekali dampak buruk ${ }^{[44-52]}$ dari pemakaian masker yang dijual dipasaran. Banyak sekali orang-orang melupakan cara tradisional yang lebih aman untuk mengatasi kulit yang berjerawat.

Salah satu pengobatan tradisional untuk penyembuhan jerawat pada wajah adalah menggunakan ekstrak ${ }^{[3-55]}$ daun binahong. Tanaman binahong (anredera cordifolia) ${ }^{[56]}$ merupakan tanaman yang menjalar dengan daun dan batang yang bewarna hijau, tanaman ini mudah tumbuh di dataran rendah ataupun di dataran tinggi. Manfaat dari daun binahong ${ }^{[57-60]}$ yang tidak diketahui oleh banyak orang adalah dapat menyembuhkan luka bakar, radang ginjal, luka setelah operasi, gatal-gatal, jerawat, mencegah stroke, maag, melancarkan peredaran darah, sereta diabetes ${ }^{[61-65]}$.

Dari hasil percobaan yang telah dilakukan oleh salah satu penduduk di desa Kapeh Panji Kabupaten Agam, Sumatera Barat, diduga daun binahong dapat mengurangi jerawat yang tumbuh di wajah dengan pemakaian rutin setiap harinya. Tujuan dari pembuatan peaper ini adalah untuk membuktikan apakah ekstrak daun binahong dapat menurunkan perutumbuhan jerawat pada wajah $^{[66-68]}$

\section{METODE}

\section{Alat dan bahan}

Peralatan yang digunakan adalah ${ }^{[69-70]}$ gunting (fengpass),wadah besar (tuppewer), wadah kecil (tuppewer), sendok (ZEBRA), lumpang dan alu (RRC),

Bahan-bahan yang digunakan ${ }^{[71-72]}$ adalah air bersih dan daun binahong segar yang diambil di desa Kapeh Panji Kab.Agam Sumatera Barat.

\section{Prosedur kerja}

Penyiapan sampel

Sampel yang digunakan diambil dari salah satu tanaman penduduk yang berada di desa Kapeh Panji, Kabupaten agam. Sampel yang diambil sebanyak 10 helai daun dengan cara memotong bagian tangkai daunnya menggunakan gunting. 


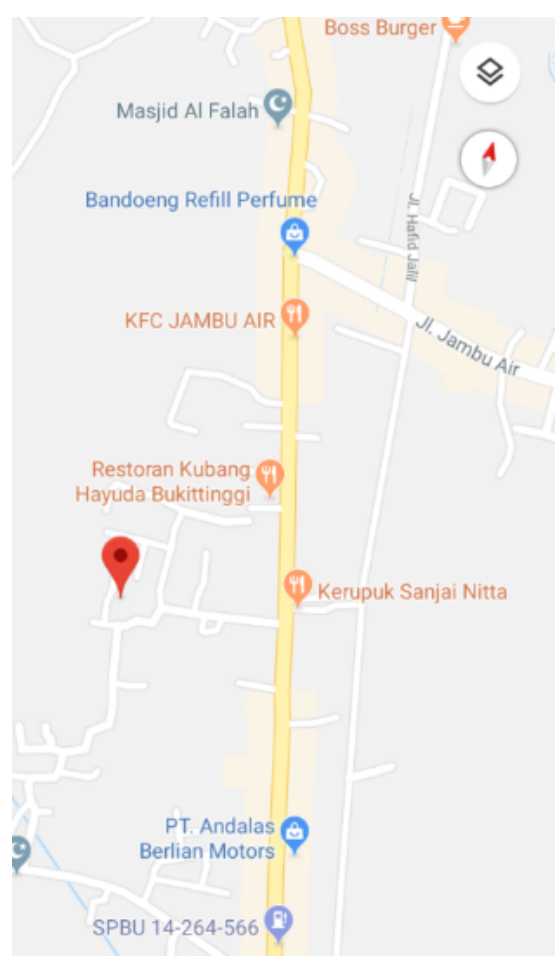

(a)

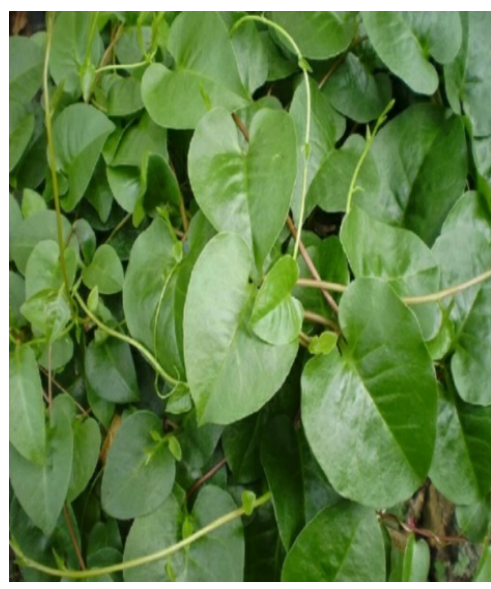

(b)

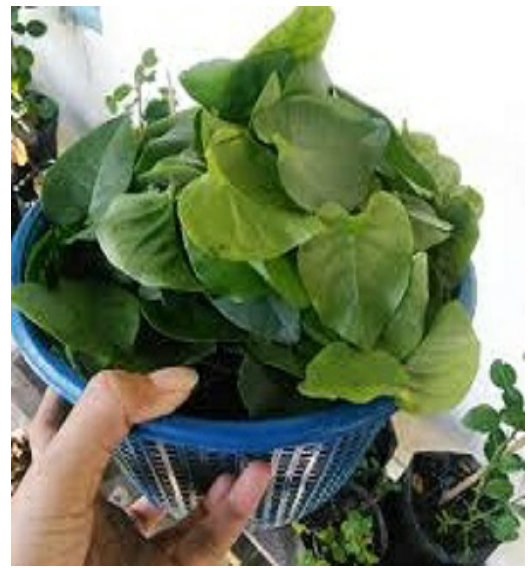

(c)

Gambar 1. Sampel bahan yang digunakan (a). Lokasi pengambilan sampel, (b). Tanaman daun binahong, (c). Daun yang sudah dipetik.

\section{Pembuatan sampel}

Tumbuhan binahong diambil bagian daunnya saja sebanyak 10 helai mengguankan gunting. Kemudian daun yang telah diambil diletakkan diwadah besar dan dicuci dengan air yang mengalir ${ }^{173-}$ ${ }^{75}$.Daun yang telah dicuci kemudian ditumbuk halus pengguanakan lumpang dan alu. Hasil tumbukan daun daun binahong dipindahkan kewadah kecil dengan bantuan sendok makan. Ekstak ini siap diuji 
cobakan kepada wajah yang berjerawat ${ }^{176-78]}$.

\section{Pengujian ekstrak}

Ekstak yang sudah didapat dilakukan pengujian terhadap seseorang yang berjerawat. Ekstrak daun ini dioleskan merata pada wajah yang berjerawat dalam keadaan bersih. Setelah ekstrak daun tersebut telah kering, barulah dicuci kembali dengan air yang bersih $^{[79-83]}$.

Didapatkan data dari penderita wajah yang berjerwat bahwa dengan pemakaian rutin setiap harinya dapat menurunkan pertumbuhan jerawat. Ekstark ini juga dapat menghilangkan bekas hitam pada wajag yang berjerawat ${ }^{[84-87]}$.

Metode ini dapat dibuat secara diagram alir sebagai berikut ${ }^{[88]}$ :

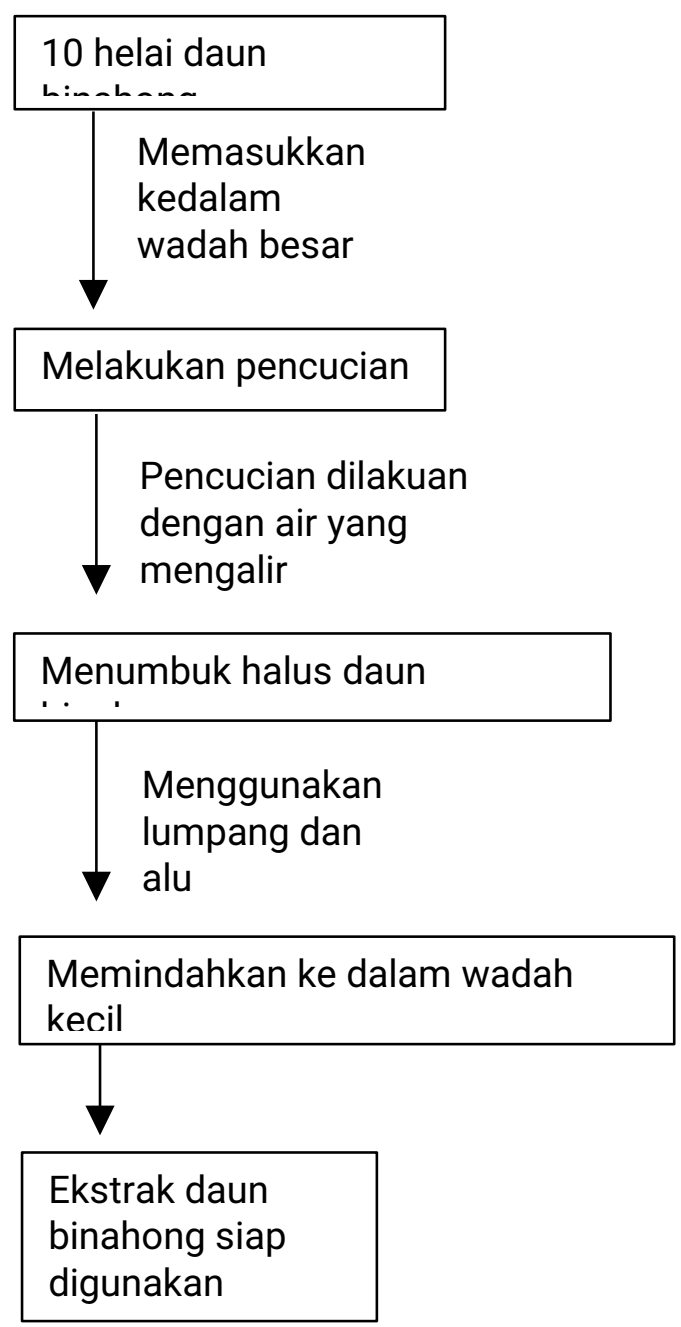


3. HASIL DAN PENGAMATAN

Pembuatan ekstrak dari 10 helai daun binahong menghasilkan 20 gram ekstrak daun binahong ${ }^{[89-90] .} 20$ gram ekstak daun binahong ini hanya dapat digunakan untuk sekali pemakaiam. Hal ini dapat dilihat dari gambar berikut:
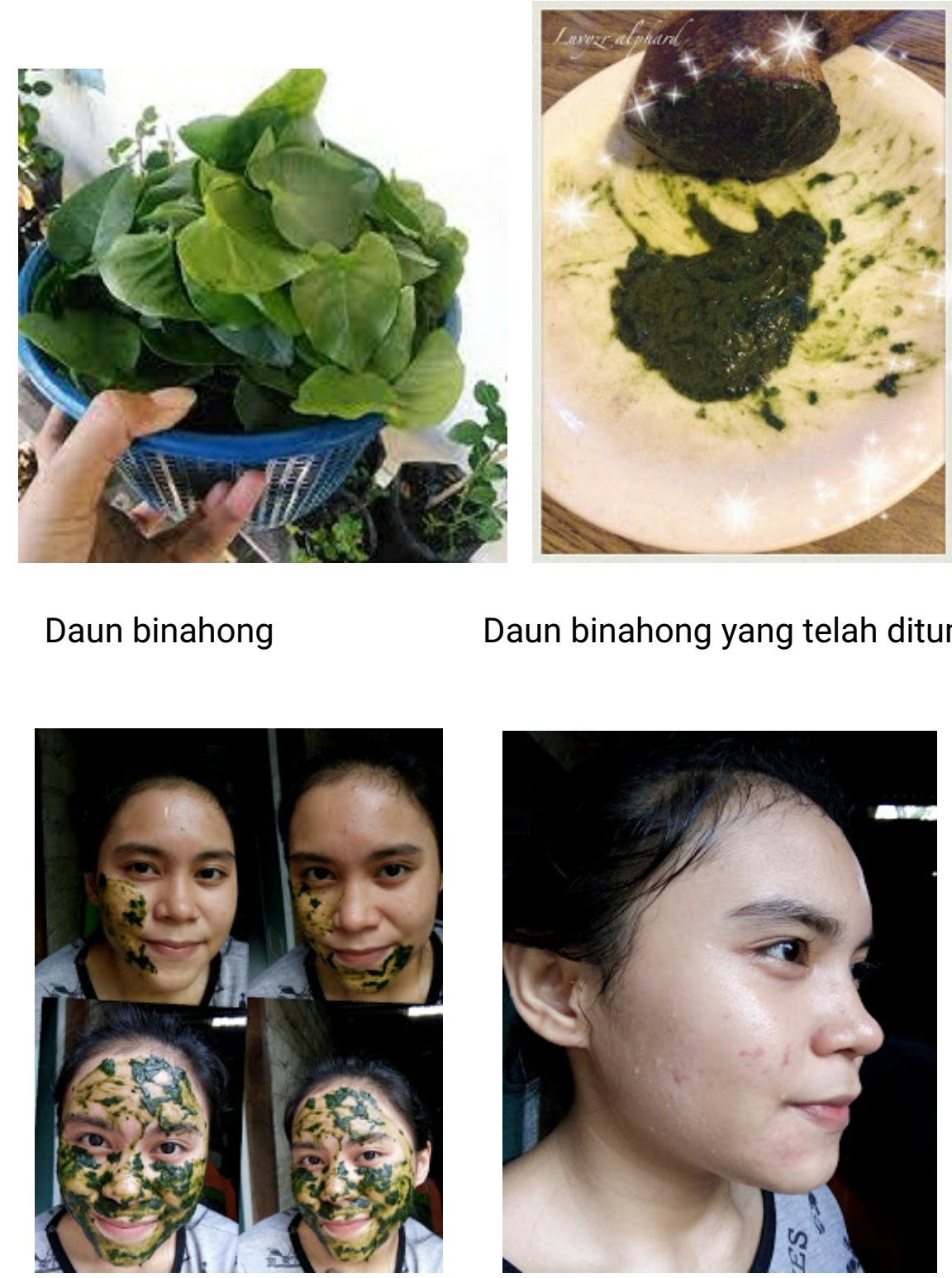

Pemberian ekstrak pada wajah wajah setelah pemakaian ekstrak daun binahong

Pengujian dilakukan terhadap wanita yang memiliki jerawat

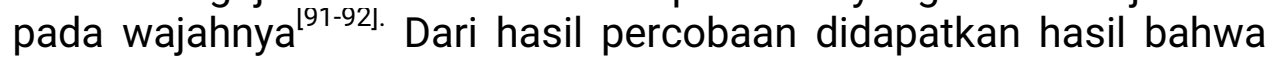
daun binahong dapat menurunkan pertumbuhan jerawat. Dapat dilihat dari tabel pengamatan berikut:

\section{Tabel 1. Hasil Pengamatan pada Pemakaian Ekstrak}




\begin{tabular}{|c|c|c|}
\hline No & Pemakaian & Hasil \\
\hline 1. & Hari ke-1 & 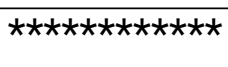 \\
\hline 2. & Hari ke-2 & 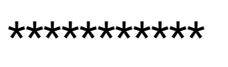 \\
\hline 3. & Hari ke-3 & 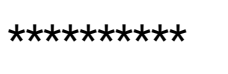 \\
\hline 4. & Hari ke-4 & 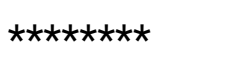 \\
\hline 5. & Hari ke-5 & 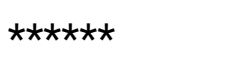 \\
\hline 6. & Hari ke-6 & 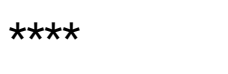 \\
\hline 7. & Hari ke-7 & ** \\
\hline
\end{tabular}

\section{PEMBAHASAN}

Tanaman binahong (anredera cordifolia) ${ }^{[92]}$ merupakan tanaman yang banyak mengandung manfaat bagi kesehatan tubuh manusia. Tanaman ini sudah banyak digunakan sebagai pengobatan oleh masyarakat di China. Tanaman yang hidup menjalar ini salah satu manfaatnya adalah dapat menurunkan pertumbuhan jerawat ${ }^{(93)}$ yang terdapat pada wajah. Dimana ekstrak daun binahong dapat menghentikan pertumbuhan bakteri pada jerawat, serta dapat mengecilkan pori-pori pada wajah.

Proses pembuatan ekstrak daun binahong ini sangatlah mudah untuk dilakukan ${ }^{[94-100]}$. Pertama yang harus kita lakukan adalah mengambil 10 helai daun binahong di daerah Kapeh Panji, Kabupaten.Agam, Sumatera Barat. Kemudian daun diletakkan di dalam wadah besar yang selanjutnya dilakulan pencucian dengan air yang mengalir ${ }^{\text {101-104]. }}$ Daun binahong yang telah dicuci ditumbuk menggunakan lumpang dan alu. Hasil tumbukan 10 helai daun binahong menghasilkan ekstrak daun binahong ${ }^{105-107]}$ seberat 20 gram. Hasil dari ekstrak daun binahong ${ }^{[108-115]}$ ini dipindahkan ke wadah yang kecil. Ekstrak ini kemudian siap dioleskan pada wajah yang berjerawat. Setelah itu ekstrak daun binahong ${ }^{[116-120]}$ dibiarkan beberapa menit hingga mengering. Setelah mengering barulah wajah dicuci dengan air yang mengaliir ${ }^{\text {[121-122] }}$

Pemakaian masker ekstrak daun binahong ini tidak terlihat perubahan secara signifikan bila digunakan hanya sekali pakai. Penggunaan ekstrak daun binahong ini sebagai masker wajah dilakukan setiap harinya untuk memperoleh hasil yang maksimum. Hal itu tentunya diiringi juga dengan menjaga kebersihan wajah dan menjaga makanan yang dikonsumsi, yaitu dengan memperbanyak makanan yang mengandung serat serta mengurangi makan yang berminyak.

Dari ekstak daun binahong ini dilakukan pengujian kepada seseorang yang memiliki wajah berjerawat. Hasil yang di dapat adalah jerawat pada wajah berkurang. Ektrak daun binahong ini juga dapat menghilangkan noda hitam yang terdapat pada wajah ${ }^{[123}$ -121]. Walaupun tidak terlihat begitu spesifik perubahan yang terjadi 
pada wajah, namun pengurangan jerawat ini terlihat setelah pemakaian rutin setiap harinya selama satu minggu. Penurunan pertumbuhan jerawat dapat dilihat dari grafik berikut:

Grafik 1. Pertumbuhan jerawat dengan pemakaian ekstrak daun binahong setiap harinya

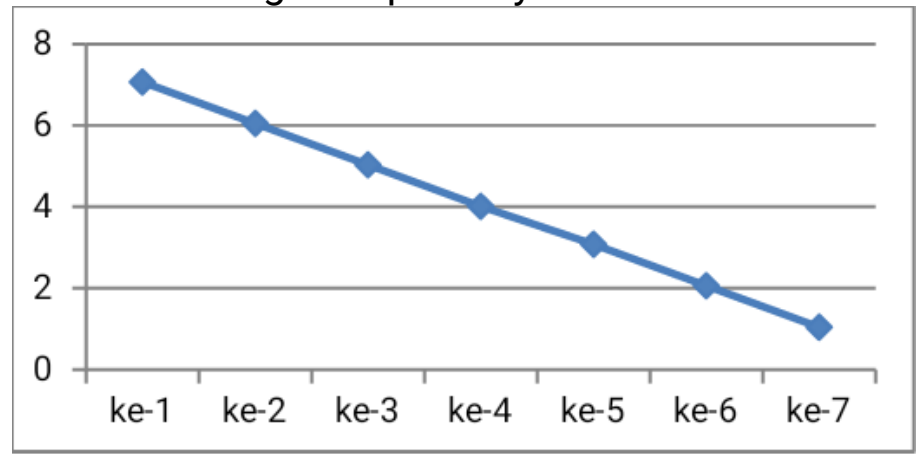

Dari kurva diatas terlihat bahwa adanya penurunan setiap harinya terhadap pemakaian ekstrak daun binahong terhadap wajah yang berjerawat. Dengan pemakaian rutin setiap harinya dan juga menjaga kebersihan wajah, masker menggunakan daun binahong bisa dapat menjadi alternatif yang mudah dan alami bagi kesehatan wajah ${ }^{l}$

Daun binahong dapat mengurangi pertumbuhan jerawat pada wajah dikarenakan daun binahong mengandung alkaloid, flavonoid ${ }^{134-135]}$, saponin, dan antioksidan yang tinggi serta antibakteri yang dapat menghabat pertumbuhan jerawat pada wajah. Berikut adalah struktur kimia dari alkaloid, flavonoid ${ }^{[136-140]}$ dan juga saponin.<smiles>NC(Cc1ccc(O)c(O)c1)C(=O)O</smiles>

Gambar 6. Alkaloid<smiles>c1ccc(CCCc2ccccc2)cc1</smiles> 


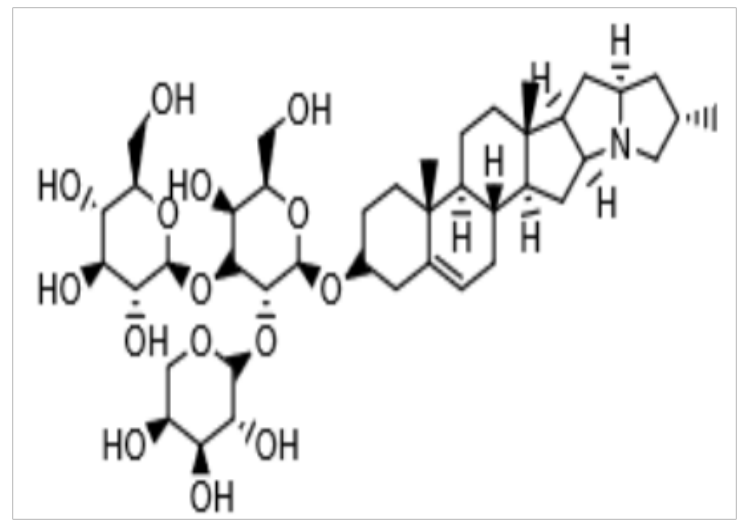

Gambar 8. Saponin

Menurut hasil penelitian flavonoid merupakan senyawaa antioksidan yang dapat merusak membran sel dan dinding sel pada bakteri $^{[141-142] .}$ Hal ini dapat menyebabkan kematian pada sel tersebut ${ }^{[143-145] .}$ Sedangkan alkaloid merupakan senyawa antibakteri yang dapat membatu mengurangi jerawat pada wajah ${ }^{[146-150]}$

\section{KESIMPULAN}

1. Ekstrak daun binahong didapatkan sebanyak 20 gram dari 10 helai daun binahong yang melalui proses penumbukan.

2. Ekstrak daun binahong dapat menurunkan pertumbuhan jerawat setelah pemakian rutin setiap harinya selama satu minggu.

3. Ekstrak daun binahong dapat menurunkan pertumbuhan jerawat karena mengandung alkaloid, flavonoid, saponin dan antioksidan yang tinggi.

\section{REFERENSI}

[1] Tasim, Lina, Santoso, I R. S., Rombang, W A. R.(2013) Analisis Pemahaman Konsep Reaksi Kimia Melalui Pendekatan Pembelajaran Langsung Pada Siswa Smp Negeri 13 Tidore Kepulauan. JSME MIPA UNIMA.Vol 1,No 3

[2] Zainul, R., Oktavia, B., Dewata, I., \& efendi, j. (2018, August 16). Studi Dinamika Molekular dan Kinetika Reaksi pada Pembelahan Molekul Air untuk Produksi Gas Hidrogen. https://doi.org/10.31227/osf.io/876s3

[3] Rahmadhanty, S., \& Zainul, R. (2018, December 24). DESIGN OF HUMAT ACID SOLID SOLUTION REACTOR THROUGH PHOTOTRANSFORMATION OF COPPER OXIDE (CuO) SEMICONDUCTOR PLATE. https://doi.org/10.31227/osf.io/yhd9

[4] Wildayati, \& Zainul, R. (2019, February 3). Magnesium Klorida (MgCl2): Karakteristik dan Dinamika Molekuler Pada $\mathrm{MgCl} 2$. https://doi.org/10.17605/OSF.IO/TFDR7 
[5] Parbuntari, H., Prestica, Y., Gunawan, R., Nurman, M. and Adella, F. (2018) "Preliminary Phytochemical Screening (Qualitative Analysis) of Cacao Leaves (Theobroma cacao L.)", EKSAKTA: Berkala IImiah Bidang MIPA, 19(2), pp. 40-45. doi: 10.24036/eksakta/vol19iss2/142.

[6] Dinata, M. and Soehardi, F. (2018) "Factor Analysis of Physics Chemistry Waters that Affects Damage Safety Cliff on the Outskirts of River Siak", EKSAKTA: Berkala IImiah Bidang MIPA, 19(2), pp. 4649. doi: $10.24036 /$ eksakta/vol19-iss2/143.

[7] Elisabeth, Jenny, Siahaan, D., Simajuntak, D. R. H.2002.Pemanfaatan Bahan Tumbuhan Sebagai Biokatalisator Dalam Produksi Minyak Sawit Kaya Asam Lemak Omega-3 1) [Using of Plant Biocatalisator for Omega-3 PUFA -Rich Palm Oil Production]. Jurnal Teknologi dan Industri Pangan. Vol 13, No 2

[8] Badrulfalah, B., Susanti, D., Joebaedi, K. and Kosasih, R. (2019) "Some Properties of Green's Matrix of Nonlinear Boundary Value Problem of First Order Differential", EKSAKTA: Berkala Ilmiah Bidang MIPA, 20(1), pp. 41-47. doi: 10.24036/eksakta/vol20-iss1/173.

[9] Pasaribu, F., Mardia, A. and Sormin, C. (2019) "Ordinal Logistic Regression with an Application to Health Service Quality in Raden Mattaher Jambi Hospital", EKSAKTA: Berkala IImiah Bidang MIPA, 20(1), pp. 35-40. doi: 10.24036/eksakta/vol20-iss1/168.

[10] Ramalisa, Y., Febriyanti, A. and Multahadah, C. (2019) "Analysis of Non Hierarchical Bomb for Collection of Community Health Degrees in Jambi and Muaro Jambi City", EKSAKTA: Berkala IImiah Bidang MIPA, 20(1), pp. 25-34. doi: 10.24036/eksakta/vol20-iss1/167.

[11] Irawan, RM Bagus.2010.Efektifitas Katalis Material Substrat Paduan Cuzn (Kuningan) Dalam Mereduksi Emisi Gas Karbon Monoksida Motor Bensin. TRAKSI mechanical engineering.Vol 10,No 2

[12] Yuliani, F., \& Zainul, R. (2018, November 13). Analisis Termodinamika Molekul Magnesium Sulphate (MgSO4). https://doi.org/10.17605/OSF.IO/96VRY

[13] Zainul, R., \& Prima, C. B. (2018, November 11). Desain Geometri Sel PV. https://doi.org/10.17605/OSF.IO/MA75V

[14] Desideria, S., Dj, L., \& Zainul, R. (2018, November 6). Deskripsi Keterampilan Proses Sains Peserta Didik Kelas XI IPA pada Materi Larutan Penyangga di SMAN 15 Padang. https://doi.org/10.17605/OSF.IO/YJV2W

[15] Jannah, A. R., Afkar, Z., \& Zainul, R. (2018, November 6). PENGEMBANGAN MEDIA PEMBELAJARAN ASAM BASA MENGGUNAKAN APLIKASI ANDROID BERBASIS CHEMISTRY TRIANGLE KELAS XI SMA/MA. Retrieved from osf.io/9azcp

[16] Sepriandi, P., Ellizar, \& Zainul, R. (2018, September 19). Pengembangan LKS Dengan Pendekatan Saintifik Berbasis Discovery Learning pada Materi Asam Basa untuk Pembelajaran Kimia Kelas XI SMA/MA. https://doi.org/10.17605/OSF.IO/YUNXJ 
[17] Hidayati, Azhar, M., \& Zainul, R. (2018, September 19). THE EFFECTIVENESS OF STRUCTURED INQUIRY BASED MODULE TO IMPROVE MENTAL MODEL OF CONCEPT MOLE. https://doi.org/10.17605/OSF.IO/VZ4NJ

[18] Mawardi, Yani, S. R., \& Zainul, R. (2018, August 31). Aktivasi Tanah Napa dan Pengaruhnya Terhadap Adsorpsi lon Timbal (II)/ Pb2+. Retrieved from osf.io/dkap2

[19] Hardeli, Sanjaya, H., \& Zainul, R. (2018, August 31). Synthesis and Electrical Properties of ZnO-ITO and Al-ITO thin Film by Spin Coating Technique Through Sol Gel Process. Retrieved from osf.io/kzr2q

[20] chaidir, zulkarnain, Fadjria, N., Armaini, \& Zainul, R. (2018, August 31). ISOLATION AND MOLECULAR IDENTIFICATION OF FRESHWATER MICROALGAE IN MANINJAU LAKE WEST SUMATERA. Retrieved from osf.io/qrwkt

[21] Murni, H. P., Dj, L., \& Zainul, R. (2018, November 6). Pengembangan Penuntun Praktikum Kimia Berorientasi Chemoentrepreneurship untuk SMA/MA Kelas XII Semester Ganjil. Retrieved from osf.io/aqk5z

[22] Irawan, RM. Bagus.2006.Pengaruh Katalis Tembaga Dan Krom Terhadap Emisi Gas Carbon Monoksida Dan Hidro Carbon Pada Kendaraan Motor Bensin.TRAKSI mechanical engineering.Vol 4,No 1

[23] Suratno, T., Rarasati, N. and Z'G. (2019) "Optimization of Genetic Algorithm for Implementation Designing and Modeling in Academic Scheduling", EKSAKTA: Berkala IImiah Bidang MIPA, 20(1), pp. 17-24. doi: 10.24036/eksakta/vol20-iss1/166.

[24] Putri, D., Anika, M. and Wahyuni, W. (2019) "Bioinformatics Study Genes Encoding Enzymes Involved in the Biosynthesis of Carotenoids Line Cassava (Manihot esculenta)", EKSAKTA: Berkala IImiah Bidang MIPA, 20(1), pp. 10-16. doi: 10.24036/eksakta/vol20iss $1 / 161$.

[25] Fati, N., Siregar, R. and Sujatmiko, S. (2019) "Addition Of Coleus Amboinicus, L Leaf's Extract In Ration To Percentage Of Carcass, Abdominal Fat, Liver And Heart Broiler", EKSAKTA: Berkala IImiah Bidang MIPA, 20(1), pp. 1-9. doi: 10.24036/eksakta/vol20-iss1/157.

[26] M., Sanjaya, H., \& Zainul, R. (2018, August 11). Characterization of napa soil and adsorption of $\mathrm{Pb}$ (II) from aqueous solutions using on column method. https://doi.org/10.31227/osf.io/t8fh9

[27] Zainul, R. (2018, August 11). ISOLATION AND IDENTIFICATION OF FRESHWATER MICROALGAE POTENTIALLY AS ANTIBACTERIAL FROM TALAGO BIRU KOTO BARU WEST SUMATERA. Retrieved from osf.io/bd58y

[28] Zainul, R. (2018, August 11). EFFECT OF TEMPERATURE AND PARTICLE MOTION AGAINST THE ABILITY OF ZnO SEMICONDUCTOR PHOTOCATALYST IN HUMIC ACID. Retrieved from osf.io/wqntk

[29] Zainul, R. (2018, June 18). CHARACTERIZATION OF NAPA 
SOIL AND ADSORPTION OF PB (II) FROM AQUEOUS

[30] Sanjaya, H. (2017) "DEGRADASI METHYLENE BLUE MENGGUNAKAN KATALIS ZnO-PEG DENGAN METODE FOTOSONOLISIS", EKSAKTA: Berkala IImiah Bidang MIPA, 18(02), pp. 21-29. doi: 10.24036/eksakta/vol18-iss02/45

[31] Zainul, R. (2018, June 18). DESIGN AND MODIFICATION OF COPPER OXIDE ELECTRODES FOR IMPROVING CONVERSION COEFFICIENT INDOORS LIGHTS (PV-CELL) PHOTOCELLS. https://doi.org/10.17605/OSF.IO/AMUHC

[32] Zainul, R. (2018, June 18). ISOLATION AND MOLECULAR IDENTIFICATION OF FRESHWATER MICROALGAE IN MANINJAU LAKE WEST SUMATERA. https://doi.org/10.17605/OSF.IO/VYDNQ

[33] Zainul, R. (2018, June 18). ISOLATION AND IDENTIFICATION OF FRESHWATER MICROALGAE POTENTIALLY AS ANTIBACTERIAL FROM TALAGO BIRU KOTO BARU WEST SUMATERA. https://doi.org/10.17605/OSF.IO/5MR9Y

[34] Widiyantoro, Ari, Khotimah,Siti, Mulyadi, Achmad Usman, Thamrin. 2009. Kemampuan Ekstrak Buah Makasar (Brucea Javanica L. Merr)Sebagai Penghambat Bakteri Propionibacterium Acnes Induser Mediator Inflamasi.Sainstek.Vol 4, No 3

[35] Dinata, A. A., Rosyadi, A. M., Hamid, S., \& Zainul, R. (2018, October 15). A Review CHEMICAL VAPOR DEPOSITION: PROCESS AND APPLICATION. https://doi.org/10.17605/OSF.IO/4X63F

[36] Putri, G. A., Hardeli, \& Zainul, R. (2018, September 25). DEVELOPMENT OF PERIODIC TABLE INTERACTIVE INSTRUCTIONAL MULTIMEDIA IN CHEMISTRY LESSON FOR Xth GRADE SMA / MA. https://doi.org/10.17605/OSF.IO/ANZY8

[37] Lubis, A. P., \& Zainul, R. (2018, November 6). Interaksi Molekuler Amonium Hidroksida. https://doi.org/10.17605/OSF.IO/VXJSE

[38] Candani, D., Ulfah, M., Noviana, W., \& Zainul, R. (2018, October 19). A Review Pemanfaatan Teknologi Sonikasi. https://doi.org/10.17605/OSF.IO/JE4CV

[39] Fatimah, P., Jumalia, R., Novianti, E. R., \& Zainul, R. (2018, October 15). A REVIEW Teknik Blended: Prinsip dan DasarDasar. https://doi.org/10.17605/OSF.IO/A7QGS

[40] Rahardja,Fanny,Puradisastra,Sugiarto,Angelina,Arlene.2010.Ak tivitas Antimikroba Gel Lidah Buaya (Aloe Vera L.) pada Acne Vulgaris yang Terinfeksi Staphylococcus sp. Secara In Vitro. Jurnal Kedokteran Maranatha. Vol 10, No 1

[41] Ruswandi, R. (2018) "Determination of Fructose Content resulted by Inulin Hydrolysis with DNS as Oxidizer", EKSAKTA: Berkala IImiah Bidang MIPA, 19(1), pp. 14-23. doi: 10.24036/eksakta/vol19iss $1 / 102$. 
[42] Santoso, B. (2018) "IDENTIFIKASI AKUIFER MENGGUNAKAN METODE GEOLISTRIK RESISTIVITAS DI DAERAH BEBANDEM, KARANG ASEM, BALI", EKSAKTA: Berkala IImiah Bidang MIPA, 19(1), pp. 24-34. doi: 10.24036/eksakta/vol19-iss1/101.

[43] Prabowo H. PENYELIDIKAN KELAYAKAN KIMIA DAN PENYEBARAN CADANGAN PASIR BESI DAERAH TIKU KABUPATEN AGAM UNTUK BAHAN BAKU SEMEN PADA PT. SEMEN PADANG. EKSAKTA [Internet]. 21Apr.2018 [cited 12May2019];19(1):39-2. Available from: http://eksakta.ppj.unp.ac.id/index.php/eksakta/article/view/121

[44] Makalalag, Indri Wirasuasty, Wullur, Adeanne, wiyono, Weny.2013.Uji Ekstrak Daun Binahong ( Anredera cordifolia Steen.) Terhadap kadar Gula Darah Pada Tikus Putih Jantan Galur Wistar (Rattus norvegicus) yang Diinduksi Sukrosa. Pharmacon. Vol 2, No 1

[45] Sumarmin, R. (2018) “PENGARUH EKSTRAK KULIT BUAH MANGGIS (GARCINIA MANGOSTANA L.) TERHADAP HISTOLOGIS PANKREAS MENCIT (MUS MUSCULUS L. SWISS WEBSTER) YANG DIINDUKSI SUKROSA", EKSAKTA: Berkala IImiah Bidang MIPA, 19(1), pp. 100-112. doi: 10.24036/eksakta/vol19-iss1/123

[46] Dinata, M., Fitridawati, F. and Putri, L. (2019) "The Study Trees Potential for Forest in Universitas Lancang Kuning Pekanbaru", EKSAKTA: Berkala IImiah Bidang MIPA, 20(1), pp. 77-85. doi: 10.24036/eksakta/vol20-iss1/176.

[47] Zainul, R. and Wardani, S. (2019) "The Hydrogen Generator Performance of Sandwich Designed 4/4 Al-Cu Plates", EKSAKTA: Berkala Ilmiah Bidang MIPA, 20(1), pp. 100-104. doi: 10.24036/eksakta/vol20-iss1/177.

[48] Syafei, N. (2019) "Events of corrosion phenomena on carbon steel pipes in environment of sea water and ammonia solutions due to the presence of sweet gas", EKSAKTA: Berkala IImiah Bidang MIPA, 20(1), pp. 86-99. doi: 10.24036/eksakta/vol20-iss1/178.

[49] Afnuhazi, R. (2019) "Bivariate Analysis on Autism Therapy using Social Skills Training in SLB YPPA Padang", EKSAKTA: Berkala IImiah Bidang MIPA, 20(1), pp. 60-76. doi: 10.24036/eksakta/vol20iss $1 / 175$.

[50] Afnuhazi, R. (2019) "Bivariate Analysis on Autism Therapy using Social Skills Training in SLB YPPA Padang", EKSAKTA: Berkala IImiah Bidang MIPA, 20(1), pp. 60-76. doi: 10.24036/eksakta/vol20iss $1 / 175$.

[51] Joebaedi, K., Susanti, D., Warwah, N., Parmikanti, K. and Badrulfalah, B. (2019) "Factors Affecting the Amount of Investment Loans in Commercial Banks with the Application of Linear Regression Analysis Methods", EKSAKTA: Berkala IImiah Bidang MIPA, 20(1), pp. 48-54. doi: 10.24036/eksakta/vol20-iss1/172.

[52] Sari, A. (2017) "POTENSI ANTIOKSIDAN ALAMI PADA EKSTRAK DAUN JAMBLANG (Syzigium cumini (L.) Skeels)”, EKSAKTA: Berkala IImiah Bidang

MIPA, 18(02), pp. 107-112. doi: 10.24036/eksakta/vol18iss02/61 
[53] Huda, N.2017.Pengaruh Ekstrak Sambiloto (Andrographis Paniculata Nees.) Terhadap Siklus Estrus Mencit (Mus Musculus L. Swiss Webster).EKSAKTA: Berkala Ilmiah Bidang MIPA, 18(02), pp. 69-76. doi: 10.24036/eksakta/vol18iss $02 / 55$.

[54] Zainul, R. and Wardani, S. (2019) "The Hydrogen Generator Performance of Sandwich Designed 4/4 Al-Cu Plates", EKSAKTA: Berkala Ilmiah Bidang MIPA, 20(1), pp. 100-104. doi: 10.24036/eksakta/vol20-iss1/177.

[55] Syafei, N. (2019) "Events of corrosion phenomena on carbon steel pipes in environment of sea water and ammonia solutions due to the presence of sweet gas", EKSAKTA: Berkala Ilmiah Bidang MIPA, 20(1), pp. 86-99. doi: 10.24036/eksakta/vol20-iss1/178.

[56] Rizki Saputra, M. and Sumarmin, R.2018.Pengaruh Ekstrak Daun Sirih Merah (Piper Crocatum Ruiz \& Pav.) Terhadap Glukosa Darah Mencit (Mus Musculus L.) Jantan Yang Diinduksi Sukrosa.EKSAKTA: Berkala IImiah Bidang MIPA, 19(1), pp. 43-55. doi: 10.24036/eksakta/vol19-iss1/124.

[57] Horiza, H., Azhar, M. and Efendi, J.2017.Ekstraksi Dan Karakterisasi Inulin Dari Umbi Dahlia (Dahlia Sp.L) Segar Dan Disimpan.EKSAKTA: Berkala Ilmiah Bidang MIPA, 18(01), pp. 31-39. doi: 10.24036/eksakta/vol18-iss01/14.

[58] Hidayat, D. (2018) "ANALISIS RESPON PENGONTROL ON-OFF PADA KENDALI UMPAN BALIK SISTEM FISIS ELEKTRONIK", EKSAKTA: Berkala Ilmiah Bidang MIPA, 19(1), pp. 118-124. doi: 10.24036/eksakta/vol19-iss1/119.

[59] Parbuntari, H., Prestica, Y., Gunawan, R., Nurman, M. and Adella, F. (2018) "Preliminary Phytochemical Screening (Qualitative Analysis) of Cacao Leaves (Theobroma cacao L.)", EKSAKTA: Berkala IImiah Bidang MIPA, 19(2), pp. 40-45. doi: 10.24036/eksakta/vol19iss2/142.

[60] Dinata, M. and Soehardi, F. (2018) "Factor Analysis of Physics Chemistry Waters that Affects Damage Safety Cliff on the Outskirts of River Siak", EKSAKTA: Berkala Ilmiah Bidang MIPA, 19(2), pp. 46-49. doi: 10.24036/eksakta/vol19-iss2/143.

[61] Sharma, V. K., Chauhan, C. S., Zainul, R., Naruka, P. S., Singh, H. P., \& Sharma, C. S. Journal of Chemical and Pharmaceutical Research (ISSN: 0975-7384).

[62] Marwoko,Muhammad Titis BudiPutri, D., Fifendy, M. and putri, M.2018.Diversitas Bakteri Endofit Pada Daun Muda Dan Tua Tumbuhan Andaleh (Morus Macroura Miq.EKSAKTA: Berkala Ilmiah Bidang MIPA, 19(1), pp. 125-130. doi: 10.24036/eksakta/vol19-iss1/122.

[63] Syafei, N. (2018) "Riset Material ANALISA FENOMENA KOROSI PELAT PIPA BAJA KARBON API 5L-X65 DALAM LARUTAN $7900 \mathrm{ML}$ AIR LAUT DAN 100 ML AMONIAK PADA KONDISI GAS CO2 DAN H2S JENUH PADA SUHU RUANG.", EKSAKTA: Berkala Ilmiah Bidang MIPA, 19(1), pp. 7-13. doi: 10.24036/eksakta/vol19-iss1/83.

[64] Hidayani, T. (2018) "GRAFTING POLIPROPILENA DENGAN MALEAT ANHIDRIDA SEBAGAI PENGIKAT SILANG DENGAN INISIATOR 
BENZOIL PEROKSIDA", EKSAKTA: Berkala IImiah Bidang MIPA, 19(1), pp. 56-62. doi: 10.24036/eksakta/vol19-iss1/127.

[65] Advinda, L. (2018) "PERTUMBUHAN STEK HORIZONTAL BATANG JARAK PAGAR (Jatropha curcas L.) YANG DIINTRODUKSI DENGAN PSEUDOMONAD FLUORESEN", EKSAKTA: Berkala IImiah Bidang MIPA, 19(1), pp. 68-75. doi: 10.24036/eksakta/vol19-iss1/129.

[66] Chatri, M., Mansyurdin, M., Bakhtiar, A. and Adnadi, P.2017.Perbandingan Komponen Minyak Atsiri Antara Daun Muda Dan Daun Dewasa Pada Hyptis Suaveolens (L.)Poit.EKSAKTA: Berkala Ilmiah Bidang MIPA, 18(02), pp. 112. doi: $10.24036 /$ eksakta/vol18-iss02/41.

[67] Zainul, R., Alif, A., Aziz, H., Arief, S., \& syukri. (2018, August 16). Photoelectrosplitting Water Mechanism at Carbon Electrode Surface using Indoor lights. Retrieved from osf.io/wkhd7

[68] Zainul, R., \& Dewata, I. (2018, August 16). Determination of pHBOD-COD and degradation in batang arau watersheds at Padang city. Retrieved from osf.io/rx6w5

[69] Mulia, M.2017.Isolasi Kumarin Dari Kulit Buah Limau Sundai (Citrus Nobilis Lour).EKSAKTA: Berkala IImiah Bidang MIPA, 18(02), pp. 137-145. doi: 10.24036/eksakta/vol18-iss02/70.

[70] Tutuarima, T.(2017)"Sifat Fisik Dan Kimia Marmalade Jeruk Kalamansi (Citrus Microcarpa) : Kajian Konsentrasi Pektin Dan Sukrosa Physical And Chemical Properties Of Marmalade Citrus Of Calamondin (Citrus Microcarpa) : Study Of Pectin And Sucrose Concentrations". EKSAKTA: Berkala IImiah Bidang MIPA, 18(02), pp. 164-172. doi: 10.24036/eksakta/vol18iss02/73.

[71] Yanuar, F., Tillah, M. and Devianto, D.(2018)"MODELING OF HUMAN DEVELOPMENT INDEX USING RIDGE REGRESSION METHOD”. EKSAKTA: Berkala IImiah Bidang MIPA, 19(2), pp. 111. doi: 10.24036/eksakta/vol19-iss2/134.

[72] Santoso, B., Setianto, S., Hasanah, M., Wijatmoko, B., Supriyana, E. and Mohammad, H.(2018)"MITIGATION OF LAND MOVEMENT USING SELF POTENTIAL METHOD IN LING -ANJUNG REGION SUMEDANG REGENCY". EKSAKTA: Berkala IImiah Bidang MIPA, 19(2), pp. 32-39. doi: 10.24036/eksakta/vol19-iss2/141.

[73] Nurfadilah, K. K., \& Zainul, R.2019. Kalium Nitrat (KNO3): Karakteristik Senyawa dan Transpor Ion.

[74] Febriani, S. S., Yolanda, T., Arianti, V. A., \& Zainul, R. (2018, October 12). A Review Solid Stated: Principles and Methode. https://doi.org/10.31227/osf.io/7us4x

[75] Febriani, S. S., Yolanda, T., Arianti, V. A., \& Zainul, R. (2019, February 14). A Review Solid Stated: Principles and Methode. https://doi.org/10.17605/OSF.IO/B9QZV

[76] P, O. M., A, L. G., S, A. Y. M., \& Zainul, R. (2019, February 14). A Review Grinding: Teknik dan Prinsip Dasar pada Pengolahan Material. https://doi.org/10.17605/OSF.IO/4RY96

[77] Husna, A. D., \& Zainul, R. (2019, February 5). Analisis Molekular 
dan Karakteristik Hidrogen Sianida (HCN). https://doi.org/10.17605/OSF.IO/3DNT7

[78] Kristy, D. P., \& Zainul, R. (2019, February 3). Analisis Molekular dan Transpor Ion Natrium Silikat. https://doi.org/10.17605/OSF.IO/VZUX9

[79] Husna, H., \& Zainul, R. (2019, February 3). A Review : Aspek Termodinamika LiNO3 dalam Larutannya. https://doi.org/10.17605/OSF.IO/FP8DX

[80] Aura, S. M., \& Zainul, R. (2019, February 3). KARAKTERISASI DAN INTERAKSI MOLEKULAR ASAM SULFAT. https://doi.org/10.17605/OSF.IO/ZRAS2

[81] Nurfadilah, K. K., \& Zainul, R. (2019, February 3). Kalium Nitrat (KNO3): Karakteristik Senyawa dan Transpor Ion. https://doi.org/10.17605/OSF.IO/U4ZXA

[82] Shafitri, M., \& Zainul, R. (2019, February 3). Vanadium Pentaoksida (V205) : Termodinamika Molecular dan Interaksi Ion dalam Larutan. https://doi.org/10.17605/OSF.IO/9C2NM

[83] Delvi, I. P., \& Zainul, R. (2019, February 3). Mercury (II) Nitrate ( $\mathrm{Hg}(\mathrm{NO} 3) 2)$ : Interaksi Molekul dan Adsorpsi $\mathrm{Hg}$ dengan Karbon Aktif. https://doi.org/10.17605/OSF.IO/KCB38

[84] Jumalia, R., \& Zainul, R. (2019, February 3). Natrium Karbonat : Termodinamika dan Transport Ion. https://doi.org/10.17605/OSF.IO/5XABN

[85] Hakimi, A., \& Zainul, R. (2019, February 1). Asam Arsenat (H3AsO4): Analisis Molekular dan Karakteristik Senyawa. https://doi.org/10.17605/OSF.IO/A3HTX

[86] Warlinda, Y. A., \& Zainul, R. (2019, February 1). Asam Posfat (H3P04): Ionic Transformation of Phosphoric Acid in Aqueous Solution. https://doi.org/10.17605/OSF.IO/JWQ54

[87] Alfionita, T., \& Zainul, R. (2019, February 1). Calcium Chloride $(\mathrm{CaCl} 2)$ : Characteristics and Molecular Interaction in Solution. https://doi.org/10.17605/OSF.IO/NMBV9

[88] Zainul, R. (2018, December 13). Studi Literasi Menggunakan Endnote Dan Aplikasi Pembantu (Google Translator, Google Cendikia, Google Sites, Chemoffice 2008, e-learning, dan Snipping Tool). https://doi.org/10.17605/OSF.IO/4P6HZ

[89] Zainul, R., Oktavia, B., Nasra, E., Arianti, V. A., Fatimah, P., Liza, Y. M., \& Setiadi, T. (2018, December 13). Studi Pengembangan dan Efektivitas Model Penulisan Karya IImiah berbasis Online Data dengan menggunakan Aplikasi Endnote bagi Guru-guru MGMP Kimia Kota Padangpanjang. https://doi.org/10.17605/OSF.IO/V4FNQ

[90] Yulis, R., Zainul, R., \& Mawardi. (2018, December 10). DESAIN DAN KARAKTERISASI SEL SURYA SISTEM ELEKTRODA TEMBAGA (I) OKSIDA (Cu2O/AI) MODEL PIPA PADA LARUTAN NATRIUM SULFAT (Na2SO4). https://doi.org/10.17605/OSF.IO/C938Q

[91] Zainul, R., Effendi, J., \& Mashuri. (2018, December 10). 
Phototransformation of Linear Alkylbenzene Sulphonate (LAS) Surfactant Using ZnO-CuO Composite Photocatalyst. https://doi.org/10.17605/OSF.IO/EPJQB

[92] Putri, G. E., Arief, S., Jamarun, N., Gusti, F. R., \& Zainul, R. (2018, December 10). Microstuctural Analysis and Optical Properties of Nanocrystalline Cerium Oxides Synthesized by Precipitation Method. Https://doi.org/10.17605/OSF.IO/PKYA7

[93] Marwoko, Muhammad Titis Budi.2013. Isolasi, Identifikasi dan Uji Aktifitas Senyawa Alkaloid Daun Binahong (Anredera cordifolia (Tenore) Steenis).Chem Info.Vol 1, No 1

[94] Suryelita, S., Etika, S. B. And Kurnia, N. S.2017.Isolasi Dan Karakterisasi Senyawa Steroid Dari Daun Cemara Natal (Cupressus Funebris Endl.).EKSAKTA: Berkala Ilmiah Bidang MIPA, 18(01), pp. 86-94. Doi: 10.24036/eksakta/vol18iss 01/23.

[95] Chaidir, z., Zainul, R., Nurakhbari, D., \& Salim, M. (2018, July 29). Optimization of Spirulina Platensis Culture for Antioxidant Production. Https://doi.org/10.17605/OSF.IO/FD6E4

[96] Sari, A.(2017)"POTENSI ANTIOKSIDAN ALAMI PADA EKSTRAK DAUN JAMBLANG (SYZIGIUM CUMINI (L.) SKEELS)".EKSAKTA: Berkala IImiah Bidang MIPA, 18(02), pp. 107-112. doi: 10.24036/eksakta/vol18-iss02/61.

[97] Zainul, R. (2018, June 18). SYNTHESIS AND ELECTRICAL PROPERTIES OF ZNO-ITO AND AL-ITO THIN FILM BY SPIN COATING TECHNIQUE THROUGH SOL GEL PROCESS. https://doi.org/10.17605/OSF.IO/5GCJ3

[98] Zainul, R. (2018, June 18). MEASUREMENT OF GLYCEMIC INDEX OF WEST SUMATERA LOCAL RICE GENOTYPES FOR HEALTHY FOOD https://doi.org/10.17605/OSF.IO/W42AC

[99] SOLUTIONS USING ON COLUMN METHOD. https://doi.org/10.17605/OSF.IO/5MGNQ

[100] Zainul, R. (2018, August 16). Effect of Temperature and Particle Motion against the ability of $\mathrm{ZnO}$ Semiconductor Photocatalyst in Humic Acid. Retrieved from osf.io/j2bqd

[101] Zainul, R. (2018, August 16). Determination of the half-life and the quantum yield of $\mathrm{ZnO}$ semiconductor photocatalyst in humic acid. Retrieved from osf.io/8tg27

[102] Zainul, R. (2018, August 16). Design and Modification of Copper Oxide Electrodes for Improving Conversion Coefficient Indoors Lights (PV-Cell) Photocells. Retrieved from osf.io/wkjqa

[103] Anhar, A., Sumarmin, R., \& Zainul, R. (2018, August 31). Measurement of Glycemic Index of West Sumatera Local Rice Genotypes for Healthy Food Selection. Retrieved from osf.io/bev8w

[104] Mawardi, Sanjaya, H., \& Zainul, R. (2018, August 31). Characterization of napa soil and adsorption of $\mathrm{Pb}$ (II) from 
aqueous solutions using on column method. https://doi.org/10.17605/OSF.IO/ZGJHQ

[105] chaidir, zulkarnain, Zainul, R., Nurakhbari, D., \& Salim, M. (2018, August 25). Optimization of Spirulina Platensis Culture for Antioxidant Production. Retrieved from osf.io/bd7nq

[106] Zainul, R. (2018, August 22). ANALISIS DISAIN GEOMETRI SEL FOTOVOLTAIK PLANAR DAN FAKTOR KONTAKNYA. https://doi.org/10.17605/OSF.IO/ZVRFJ

[107] Zainul, R. (2018, August 16). DISAIN, METODE DAN PENGGUNAAN SOFTWARE PEMBELAJARAN KIMIA BERBASIS IT UNTUK AKTIVITAS KELAS DAN LABORATORIUM BERBASIS INKUIRI TERBIMBING. Retrieved from osf.io/s5pn6

[108] Lusi, D. F., Yerimadesi, \& Zainul, R. (2018, November 6). EFEKTIVITAS MODUL LARUTAN ELEKTROLIT DAN NONELEKTROLIT BERBASIS DISCOVERY LEARNING TERHADAP KETERAMPILAN BERPIKIR KRITIS DAN HASIL BELAJAR SISWA KELAS X MIPA SMAN 2 BUKITTINGGI. https://doi.org/10.17605/OSF.IO/X2P4C

[109] Handayani, D. P., Zainul, R., \& Azra, F. (2018, November 6). PENGEMBANGAN MULTIMEDIA PREZI BERBASIS PROBLEM BASED LEARNING (PBL) PADA MATERI HUKUM-HUKUM DASAR KIMIA KELAS X IPA DI SMAN 1 BUKITTINGGI. Retrieved from osf.io/dwf42

[110] Firdaus, A., \& Zainul, R. (2018, November 6). SESIUM KLORIDA (CsCl): TRANSPORT ION DALAM LARUTAN. https://doi.org/10.17605/OSF.IO/R4H8K

[111] Putri, D. F., Ritonga, H. M., Murdiati, V., \& Zainul, R. (2018, October 15). A REVIEW WHAT IS HYDROTHERMAL ? https://doi.org/10.17605/OSF.IO/R2KGZ

[112] Awalliyah, A., Ikhwan, H., Nugiasari, V., \& Zainul, R. (2018, October 15). A REVIEW PRINSIP DASAR MILLING DALAM SINTESIS MATERIAL. https://doi.org/10.17605/OSF.IO/JUAF5

[113] Iskandar, I., Horiza, H. and Fauzi, N. (2017) "EFEKTIVITAS BUBUK BIJI PEPAYA (Carica Papaya Linnaeaus) SEBAGAI LARVASIDA ALAMI TERHADAP KEMATIAN LARVA AEDES AEGYPTY TAHUN 2015", EKSAKTA: Berkala IImiah Bidang MIPA, 18(01), pp. 12-18. doi: 10.24036/eksakta/vol18-iss01/12.

[114] Iskandar, I., Horiza, H. and Fauzi, N. (2017) “EFEKTIVITAS BUBUK BIJI PEPAYA (Carica Papaya Linnaeaus) SEBAGAI LARVASIDA ALAMI TERHADAP KEMATIAN LARVA AEDES AEGYPTY TAHUN 2015", EKSAKTA: Berkala IImiah Bidang MIPA, 18(01), pp. 12-18. doi: 10.24036/eksakta/vol18-iss01/12.

[115] Ramli R, Jonuarti R, Hartono A. ANALISIS STRUKTUR NANO DARI LAPISAN TIPIS COBALT FERRITE YANG DIPREPARASI DENGAN METODE SPUTTERING. EKSAKTA [Internet]. 28Apr.2017 [cited 12May2019];18(01):46-3. Available from: http://eksakta.ppj.unp.ac.id/index.php/eksakta/article/view/16

[116] Handayani, D. (2017) "KARAKTERISTIK CENDAWAN DARK SEPTATE ENDOPHYTE (DSE) PADA AKAR TANAMAN JAGUNG DAN PADI", 
EKSAKTA: Berkala IImiah Bidang MIPA, 18(01), pp. 61-68. doi: 10.24036/eksakta/vol18-iss01/20.

[117] Sarjani, F., Sri Sumantyo, J. T. and Yohandri, Y. (2017) "PENGOLAHAN CITRA SATELIT ALOS PALSAR MENGGUNAKAN METODE POLARIMETRI UNTUK KLASIFIKASI LAHAN WILAYAH KOTA PADANG", EKSAKTA: Berkala IImiah Bidang MIPA, 18(01), pp. 69-77. doi: 10.24036/eksakta/vol18-iss01/21.

[118] Permana, D. (2017) "MODEL STOKASTIK RANTAI MARKOV EMPAT STATUS PADA PENENTUAN NILAI HIDUP PELANGGAN", EKSAKTA: Berkala Ilmiah Bidang MIPA, 18(01), pp. 78-85. doi: 10.24036/eksakta/vol18-iss01/22.

[119] Saiya, A. (2017) "ANALISIS RESIDU KLORPIRIFOS DALAM SAYURAN KUBIS DENGAN METODE HPLC DI BEBERAPA PASAR TRADISIONAL DI SULAWESI UTARA", EKSAKTA: Berkala IImiah Bidang MIPA, 18(02), pp. 77-85. doi: 10.24036/eksakta/vol18-iss02/57.

[120] Syafei, N. (2017) "ANALISA FENOMENA KOROSI PELAT PIPA BAJA KARBON API 5L-X65 DALAM LARUTAN 250 ML ASAM ASETAT DAN $4750 \mathrm{ML}$ AQUADES PADA KONDISI GAS CO2 DAN H2S JENUH PADA SUHU RUANG", EKSAKTA: Berkala IImiah Bidang MIPA, 18(02), pp. 113-120. doi: 10.24036/eksakta/vol18-iss02/63.

[121] Susilaningrum, D. (2017) “PEMODELAN REGRESI LOGISTIK PADA FAKTOR YANG MEMPENGARUHI PHBS PADA RUMAH TANGGA PENDERITA TBC DI PESISIR SURABAYA", EKSAKTA: Berkala IImiah Bidang MIPA, 18(02), pp. 121-128. doi: 10.24036/eksakta/vol18iss02/65.

[122] Setianto, S. (2017) "ANALISA KUANTITATIF CAMPURAN SENYAWA OKSIDA SEBAGAI DASAR IDENTIFIKASI KANDUNGAN BAHAN SUMBER DAYA ALAM Studi Kasus : Kandungan Mineral pada Pasir Besi di Pesisir Pantai Selatan, Jawa Barat", EKSAKTA: Berkala Ilmiah Bidang MIPA, 18(02), pp. 173-177. doi: 10.24036/eksakta/vol18iss02/74.

[123] Amananti, W. (2017) "ANALISIS MIKROSTRUKTUR LAPISAN TIPIS TiO2:ZnO YANG DIDEPOSISIKAN DIATAS SUBTRAT KACA DENGAN METODE SPRAY COATING UNTUK DEGRADASI LIMBAH ZAT WARNA", EKSAKTA: Berkala IImiah Bidang MIPA, 18(02), pp. 210215. doi: 10.24036/eksakta/vol18-iss02/81.

[124] Nasir, M. (2017) "PENGARUH WAKTU HIGH ENERGY MILLING TERHADAP KARAKTERISTIK NANOKAOLIN CAPKALA ASAL KALIMANTAN BARAT", EKSAKTA: Berkala Ilmiah Bidang MIPA, 18(02), pp. 200-209. doi: 10.24036/eksakta/vol18-iss02/78.

[125] Yanuar, F., Tillah, M. and Devianto, D. (2018) "Modeling of Human Development Index Using Ridge Regression Method", EKSAKTA: Berkala Ilmiah Bidang MIPA, 19(2), pp. 1-11. doi: 10.24036/eksakta/vol19-iss2/134.

[126] Syafei, N., Hidayat, D., Emilliano, E. and Men, L. (2018) "Analysis Cracking Corrosion on Carbon Steel Pipes API 5L-X65 In Solution $7700 \mathrm{ml}$ Aquades, $250 \mathrm{ml}$ Acetic Acid and $50 \mathrm{ml}$ Ammonia with Gas $\mathrm{CO} 2$ and H2S in Saturation Condition", EKSAKTA: Berkala Ilmiah Bidang MIPA, 19(2), pp. 21-31. doi: 10.24036/eksakta/vol19iss2/138.

[127] Santoso, B., Setianto, S., Hasanah, M., Wijatmoko, B., Supriyana, E. 
and Mohammad, H. (2018) "Mitigation of Land Movement using Self Potential Method in Ling-Anjung Region Sumedang Regency", EKSAKTA: Berkala Ilmiah Bidang MIPA, 19(2), pp. 32-39. doi: 10.24036/eksakta/vol19-iss2/141.

[128] Harahap, F. and Lubis, L. (2018) "Analysis of Heavy Metals Distribution in the River Town of Hamasaki's Rod Padangsidimpuan", EKSAKTA: Berkala Ilmiah Bidang MIPA, 19(2), pp. 50-56. doi: 10.24036/eksakta/vol19-iss2/149.

[129] Badrulfalah, B., Irianingsih, I. and Joebaedi, K. (2018) "Some Operations on Mixed Monotone Operator in Banach Spaces", EKSAKTA: Berkala IImiah Bidang MIPA, 19(2), pp. 57-61. doi: 10.24036/eksakta/vol19-iss2/150.

[130] Joebaedi, K., Parmikanti, K. and Badrulfalah, B. (2018) "First Order Space Time Autoregressive Stationary Model on Petroleum Data", EKSAKTA: Berkala Ilmiah Bidang MIPA, 19(2), pp. 62-69. doi: 10.24036/eksakta/vol19-iss2/152.

[131] Sofyanita, S. and Octaria, Z. (2018) "Fenthion Compound Degradation in the Pesticide Bayleton 500 ec in Sonolysis, Ozonolysis and Sonozolysis with Addition of TiO2-anatase", EKSAKTA: Berkala IImiah Bidang MIPA, 19(2), pp. 70-79. doi: 10.24036/eksakta/vol19-iss2/153.

[132] Vauzia, V. and Gusmira, E. (2018) "The Response of Jabon Seeds Germination (Anthocephalus cadamba (Roxb.)Miq.) against the Duration of Combustion and Illumination", EKSAKTA: Berkala IImiah Bidang MIPA, 19(2), pp. 80-87. doi: 10.24036/eksakta/vol19iss2/154. Selawa,Widya,Runtuwene,Max

$R$ J,Citraningtyas,Gayatri.2013.Kandungan Flavonoid Dan Kapasitas Antioksidan Total Ekstrak Etanol Daun Binahong [Anredera Cordifolia(Ten.)Steenis.].Pharmacon.Vol 2, No 1

[133] Wartini Harijono, Ni Made, Susanto, Tri, Rurini Retnowati, Yunianta.2012. TINGKAT KESUKAAN DAN SENYAWA PENYUSUN EKSTRAK FLAVOR DAUN SALAM (EUGENIA POLYANTHA WIGHT.) DARI BEBERAOA METODE SEPARASI.Agrotekno.Vol. 14, No.2

[134] Iryani, I., Iswendi, I. and Katrina, I. T.2017.Uji Aktivitas Anti Diabetes Mellitus Senyawa Metabolit Sekunder Fraksi Air Dari Beras Ketan Hitam ( Oryza Satival. Var Glutinosa) Pada Mencit Putih.EKSAKTA: Berkala IImiah Bidang MIPA, 18(01), pp. 54-60. doi: 10.24036/eksakta/vol18-iss01/17.

[135] Rahmawati,Lina.2013.Isolasi,Identifikasi Dan Uji Aktivitas Antioksidan Senyawa Flavonoid Daun binahong (Anredera Cordifolia (Ten.)Steenis).Chem Info.Vol 1,No 1

[136] Senyawa Metabolit Sekunder Fraksi Air Dari Beras Ketan Hitam ( Oryza Satival. Var Glutinosa) Pada Mencit Putih.EKSAKTA: Berkala IImiah Bidang MIPA, 18(01), pp. 54-60. doi: 10.24036/eksakta/vol18-iss01/17

[137] Setiadi, T., \& Zainul, R. (2019, April 4). Pengembangan E-Modul Asam Basa Berbasis Discovery Learning Untuk Kelas XI SMA/MA. https://doi.org/10.17605/OSF.IO/K7U5G 
[138] Liza, Y. M., Yasin, R. C., Maidani, S. S., \& Zainul, R. (2019, February 14). SOL GEL: PRINCIPLE AND TECHNIQUE (A REVIEW). https://doi.org/10.17605/OSF.IO/DNP8R

[139] Irawan, D. E., Prasnowo, M. A., Rahim, R., Pranolo, A., Kurniasih, N., Putri, L. D., ... Zainul, R. (2018, December 10). INARXiv The preprint server of Indonesia. https://doi.org/10.17605/OSF.IO/9JQXY

[140] Tamarani, A., Zainul, R., \& Dewata, I. (2018, December 9). Preparation and Characterization of XRD Nano Cu-TiO2 using Sol-Gel Method. https://doi.org/10.17605/OSF.IO/DTPYE

[141] Zainul, R., \& Prima, C. B. (2018, December 9). TEKNOLOGI MATERIAL MAJU Prinsip Dasar dan Aspek Rekayasa. https://doi.org/10.17605/OSF.IO/9HB7N

[142] Yanti, C. F., \& Zainul, R. (2018, December 2). A Review $\mathrm{Ba}(\mathrm{OH}) 2$ : Transpor Ionik pada Barium Hidroksida di dalam Air dengan Konsep Termodinamika. https://doi.org/10.17605/OSF.IO/5G7EW

[143] Dwynda, I., \& Zainul, R. (2018, November 19). Boric Acid (H3(BO3): Recognize The Molecular Interactions in Solutions. https://doi.org/10.17605/OSF.IO/8CJHR

[144] Feronika, N. I., \& Zainul, R. (2018, November 19). Kalium Permanganat: Termodinamika Mengenai Transport lonik dalam Air. https://doi.org/10.17605/OSF.IO/V34ND

[145] Sari, M., \& Zainul, R. (2018, November 19). Kalium Dikromat (K2Cr207) Spektroskopi dan Transpor K2Cr2O7. https://doi.org/10.17605/OSF.IO/Z54J9

[146] Artika, P. I., \& Zainul, R. (2018, November 19). Potassium Bromide $(\mathrm{KBr})$ : Transformasi ionik dan sifat temodinamika dalam Larutan. https://doi.org/10.17605/OSF.IO/QJZ58

[147] Yurmaniati, \& Zainul, R. (2018, November 18). SILVER SULFATE (Ag2SO4): MOLECULAR ANALYSIS AND ION TRANSPORT. https://doi.org/10.17605/OSF.IO/RS4QU

[148] Zainul, R. (2018, June 18). DETERMINATION OF THE HALF TIME AND THE QUANTUM YIELD OF ZnO SEMICONDUCTOR PHOTOCATALYST IN HUMIC ACID. https://doi.org/10.17605/OSF.IO/JNCE5

[149] Zainul, R. (2018, June 18). OPTIMIZATION OF SPIRULINA PLANTESIS CULTURE FOR ANTIOXIDANT PRODUCTION. https://doi.org/10.17605/OSF.IO/FD6E4

[150] Zainul, R. (2018, June 18). EFFECT OF TEMPERATURE AND PARTICLE MOTION AGAINST THE ABILITY OF ZnO SEMICONDUCTOR PHOTOCATALYST IN HUMIC ACID. https://doi.org/10.17605/OSF.IO/JM6UH 